Research Article

\title{
Investigation of Water Leakage of Metro Segments Caused by Metro Underpass Structures
}

\author{
Xiao Liang $\mathbb{D}^{1,2}$ Taiyue Qi $\mathbb{D}^{1,2}$ Zhiyi Jin $\mathbb{C D}^{1,2}$ Pengtao Chen $\mathbb{D}^{1,2}$, Bo Lei $\mathbb{D}^{1,2}$ \\ Wangping Qian $\mathbb{D},{ }^{3}$ and Xianyu Wang $\mathbb{D}^{4}$ \\ ${ }^{1}$ Key Laboratory of Transportation Tunnel Engineering, Ministry of Education, Chengdu, China \\ ${ }^{2}$ School of Civil Engineering, Southwest Jiaotong University, Chengdu, China \\ ${ }^{3}$ School of Transportation and Civil Engineering, Nantong University, Nantong, China \\ ${ }^{4}$ China Railway Southwest Research Institute Company Limited, Chengdu, China
}

Correspondence should be addressed to Taiyue Qi; qitaiyue85@126.com

Received 25 October 2020; Revised 1 March 2021; Accepted 10 March 2021; Published 24 March 2021

Academic Editor: Meng Jingjing

Copyright (c) 2021 Xiao Liang et al. This is an open access article distributed under the Creative Commons Attribution License, which permits unrestricted use, distribution, and reproduction in any medium, provided the original work is properly cited.

Water leaking into metro segments is related directly to the presence of underground water. However, to date, the underground confined water channels formed by metro underpass reinforcement structures have not been considered as causes of the problem. In the present study, based on field investigations and geological data, confined water is identified as the source of segment leakage on Line 5 of Hangzhou Metro in China. It is then hypothesized that the problem stems from an underground confined water channel formed under the reinforced structure of the subway. Numerical simulations predict a settlement difference of 8-10 mm between the reinforcement area and the weak strata, and field monitoring data show this difference to be $8.62 \mathrm{~mm}$. This consistency between the numerical simulations and the field measurements verifies the hypothesis. Finally, given the causes of underground confined water channels, corresponding technical measures such as piecewise secondary grouting are proposed to cut them off and avoid metro-segment leakage. The present research results contribute to the causes of and the laws governing the metro-segment leakage that occurs at subway stations and other reinforced structures.

\section{Introduction}

The main problem affecting metro tunnels is water leaking into their segments, herein referred to as metro-segment leakage (MSL), which has a direct effect on the operating environment and safety of metro trains [1]. To ensure the safety of metro projects, there have been many studies of the causes and effects of MSL, some of which are summarized below.

Ye et al. [2] investigated many cases of tunnel leakage and proposed as the main cause the fact that a large amount of groundwater could not permeate quickly from the initial support after being discharged. Xu et al. [3] used the finite element (FE) method to subject the seepage and stress fields of the surrounding rocks and structures to coupling analysis to obtain the distribution rules for the stress, displacement, and pore water pressure during construction; the results showed groundwater to be the direct source of the water flow causing tunnel leakage. Wang et al. [4] studied seepage in newly built tunnels by gathering statistics on the seepage in tunnel projects for the Jiangxi expressway, and they concluded that the tunnel seepage was uneven due to the greatly varying state of the fissure water in the surrounding rock. Wang et al. [5] summarized the hazards caused by groundwater seepage in tunnel engineering, analyzed the conditions and mechanism of groundwater seepage using a theoretical model, and then proposed that the amount of water inflow in a tunnel depends mainly on the permeability of the soil layer. Li et al. [6] used a numerical model to analyze the formation of leakage problems in a naked tunnel and concluded that (i) groundwater leakage is one of the main causes and (ii) the fracture zone is an area of severe seepage. Wei et al. [7] gathered statistics from existing research on tunnel leakage and summarized the causes and hazards of leakage; they identified causes from before, during, and after construction, such as unreasonable production and maintenance of pipe pieces before construction, 
poor grouting quality during construction, and uneven settlement after construction.

Shin et al. [8] used nonlinear coupled FE analysis to study how the long-term predicted response of the foundation and lining differ under different hydrological conditions; they compared the permeability of the lining with that of the soil under different hydraulic boundary conditions and introduced a method for simulating the limited permeability of the lining. Liu et al. [9] proposed a method for predicting the amount of groundwater inflow in anisotropic and isotropic confined aquifers over time; they applied the method to field analysis of groundwater inflow in Guangzhou Metro Line 7 and an underground tunnel in the city of Huizhou in Guangdong Province, and the measurements showed the method to be effective. Wu et al. [10] proposed a new numerical method for simulating the local seepage of shield tunnel linings based on the engineering background of Shanghai Metro tunnels, and they used the proposed method to study how groundwater seepage influences foundation consolidation and tunnel deformation. Shin et al. [11] used a numerical simulation method to build a two-dimension model and studied the coupled mechanical and hydraulic interaction between the segment lining and the surrounding ground; the results showed that hydraulic degradation leads to significant changes in pore water pressure and structural properties and accelerates leakage. Wu et al. $[12,13]$ analyzed the factors affecting leakage and studied its impact in depth by establishing a three-dimensional fluid-solid coupled FE model. The results showed that the leakage at the retaining wall changes will cause the change of water flow direction and the decrease of groundwater level.

Previous research on tunnel seepage was directed mainly at the following aspects: (i) causes of leakage in terms of geological conditions (e.g., rock structure) and construction (e.g., insufficient waterproof design); (ii) influence of seepage water (e.g., on the deformation of a subsidence tunnel with surface subsidence water level and the failure of pipe segments); (iii) relevant laws for seepage and water leakage (e.g., how groundwater flow changes over time and the prediction of water leakage). However, there have been few studies to date on the relationship between tunnel underpass reinforcement structures and leakage, and such structures have not been considered as causes of leakage.

Based on the engineering problems in Hangzhou Metro Line 5, this paper analyzes and verifies the hypothesis that the settlement difference will form underground confined water channel (UCWC) when the tunnel passes through the station. The UCWC leads the confined water flow to the region where there is no groundwater and leads to disease later. First of all, the paper introduces the engineering background and the leakage situation. The hypothesis of the source and flow path of the leakage are proposed based on the field investigations and engineering data. Next, the above hypothesis is verified by means of numerical simulation, settlement monitoring, and water composition analysis. Finally, the technical measures to cut off UCWC are put forward.

\section{Engineering Background}

2.1. Engineering Problems. Hangzhou Metro Line 5 starts at Jinxing Station in Yuhang District and ends at Maiden Bridge Station in Xiaoshan District, running through the northwest of Hangzhou's main urban area, the central urban area, and the southern area. Line 5 passes through seven urban districts, including those of Yuhang, Xihu, and Xiaoshan, and is a major passenger flow channel. It has a total length of $56.21 \mathrm{~km}$ and a general $Z$-shaped trend, as shown in Figure 1. Along that length, the geological conditions between South Railway Station (SRS) and Tonghui Road Station are complex, involving shield tunnel construction, mining tunnel construction, and shaft construction. Both ends of the interval tunnel were constructed by the shield method, while the middle section was constructed by mining. The length of the tunnel constructed by the shield method in the right line is $1218.20 \mathrm{~m}$, and the length of the tunnel constructed by the shield method in the left line is $1226.17 \mathrm{~m}$.

Based on the engineering geological survey data, the strata comprise mainly silt and silty clay, silty clay, and silty clay with sand. The groundwater in the shield zone is mainly the pore water of quaternary loose rocks. According to the waterbearing medium, occurrence conditions, hydrologic properties, and hydraulic characteristics of the groundwater, it can be divided into phreatic water and confined water. The static water level of the phreatic water is $2.0 \mathrm{~m}$, and it varies seasonally. The phreatic water is distributed mainly in the shallow filling soil layer, i.e., the silty clay layer (in the range of rings 0-150), with less water. It is mainly recharged by atmospheric precipitation and lateral runoff and discharged via evaporation and lateral runoff. The confined water is distributed mainly within the range of rings 50-150 of the shield, as indicated in Figure 1. It is contained in the silty clay with sand, buried more than $50 \mathrm{~m}$ deep, and rich in water. The water barrier layer comprises the overlying silty soil, which is rich in water and has obvious characteristics of deep burial and large water volume.

The research area is located in Xiaoshan District and includes SRS, which has a frame structure that is divided into one underground floor and two above-ground floors. The station foundation is a raft foundation with many piles below. The section of the tunnel under SRS mainly involves mucky clay and silty clay. The profile of the SRS section is shown in Figure 2. The distance between the tunnel lines within the tunnel crossing range is $10.8 \mathrm{~m}$, and the top of the tunnel is buried at a depth of $20-25 \mathrm{~m}$. The outer diameter of a tunnel segment is $6.2 \mathrm{~m}$, the inner diameter is $5.5 \mathrm{~m}$, the segment thickness is $0.35 \mathrm{~m}$, and the ring width is $1.2 \mathrm{~m}$. Having excavated the left tunnel for $12 \mathrm{~m}$, excavation began on the right tunnel, after which both tunnels remained synchronized until the end. Excavation of shield machines used for EPB composites earth pressure balance shield machine, produced by German Herrenknecht AG. Each shield tunneling machine had a construction mileage of less than $3 \mathrm{~km}$ and was comprised of systems for excavation, ballasting, ballasting soil improvement, pipe piece installation, grouting, power system control, and measurement guidance, with advanced drilling and grouting capability. The main parameters of the shield machines are given in Table 1. 


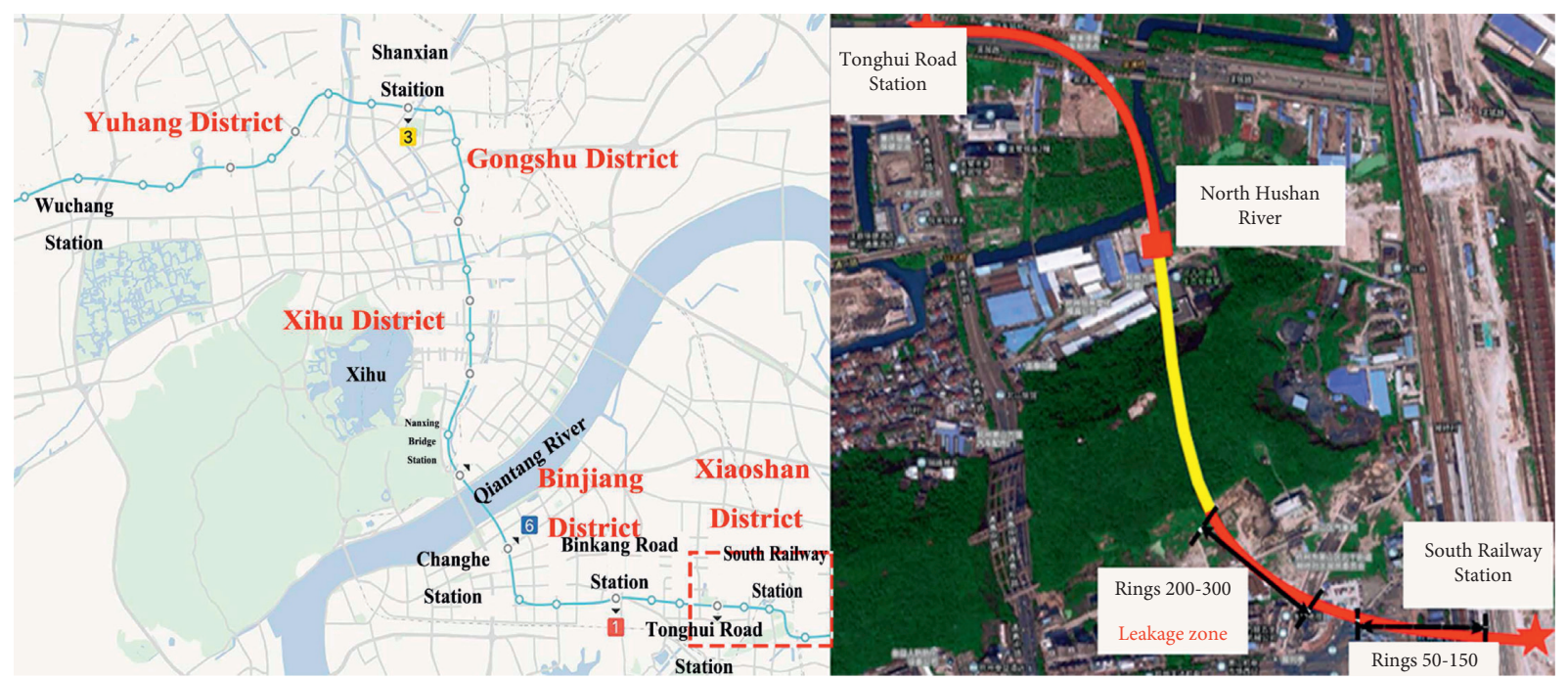

Figure 1: Schematic diagram of Hangzhou Metro Line 5.

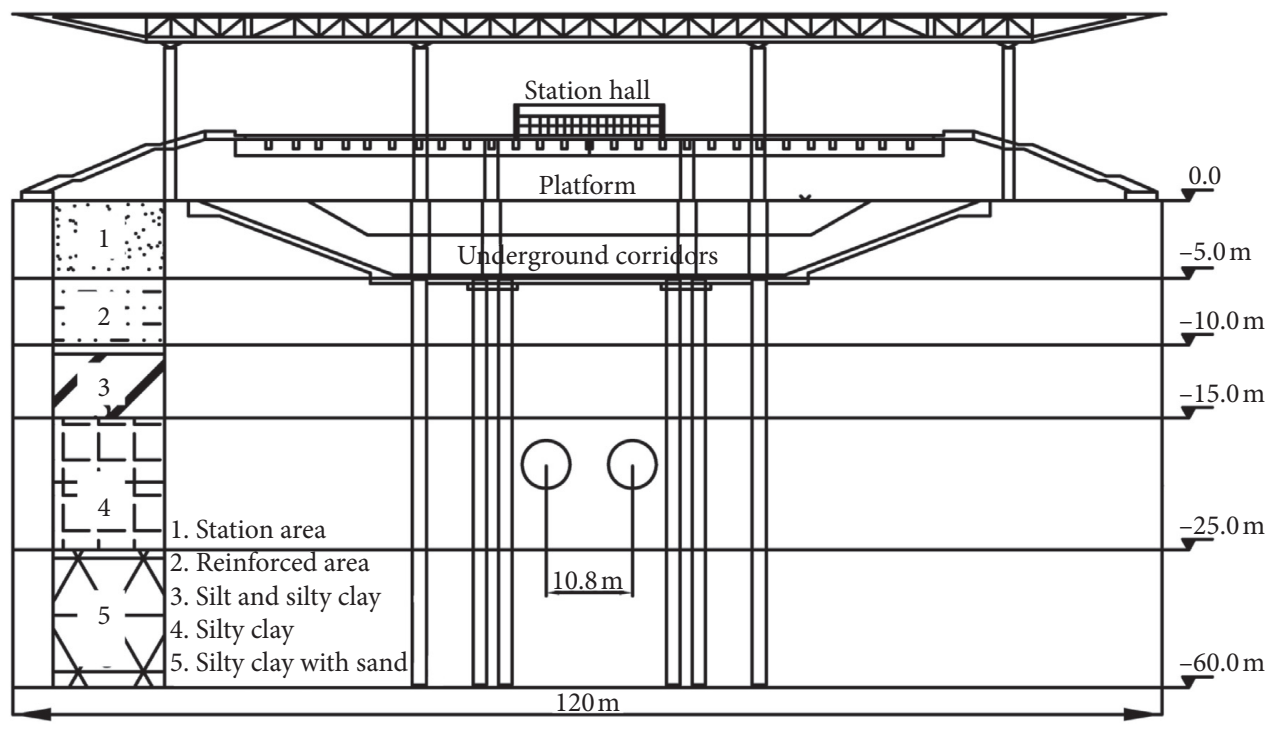

Figure 2: Profile of Hangzhou South Railway Station.

TABLE 1: Main parameters of Herrick shield machine.

\begin{tabular}{lcc}
\hline Number & Item & Parameter \\
\hline 1 & Diameter/length of shield machine & $6.450 / 8.000 \mathrm{~m}$ \\
2 & Cutter disc device type/opening rate $/ 36 \%$ \\
3 & Cutting disc drive & Hydraulic slewing drive \\
4 & Radius of the adaptive minimum curve & $250 \mathrm{~m}$ \\
5 & Maximum heading speed & $8 \mathrm{~cm} / \mathrm{min}$ \\
6 & Number of thrust cylinders/maximum total thrust & $16 \mathrm{sets}$ of twin cylinders $/ 42575 \mathrm{kN}$ \\
7 & Synchronous grouting system grouting pump & 2 \\
8 & Grouting system cleaning loop & 1 \\
9 & Shield tail seal/shield tail grease injection hole & 3 rows of seal plate brushes $/ 2 \times 6$ \\
10 & Soil pressure sensor/gate emergency closing device & $5 / 1$ \\
\hline
\end{tabular}

When the tunnel was excavated to the 200-300 ring section, MSL appeared and the damage was serious, as shown in Figure 3(a). Having found MSL on site, grouting was implemented to plug the leakage. However, in the process of grouting, the following abnormal conditions arose: (i) the grouting pressure of the two grouting ports at the end of the shield increased gradually and exceeded the reasonable value, being possibly as high as $1.00 \mathrm{MPa}$ in 


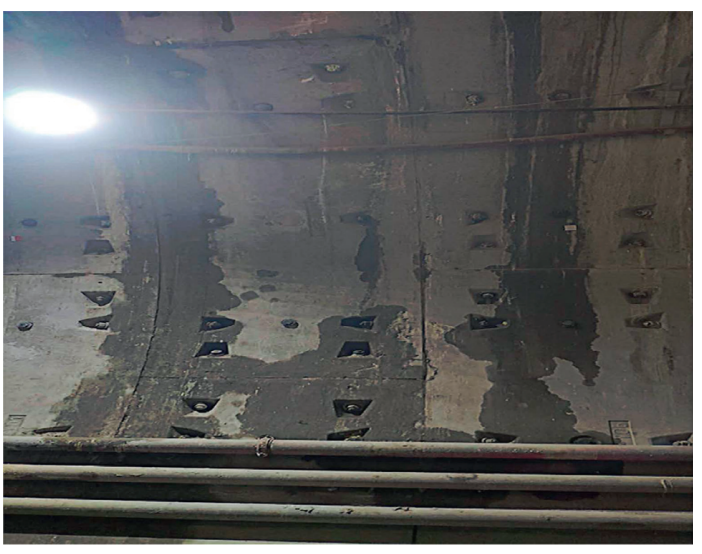

(a)

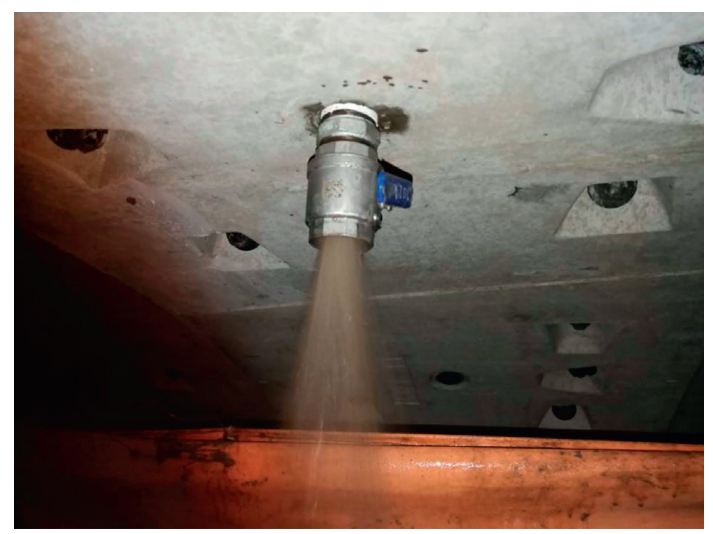

(c)

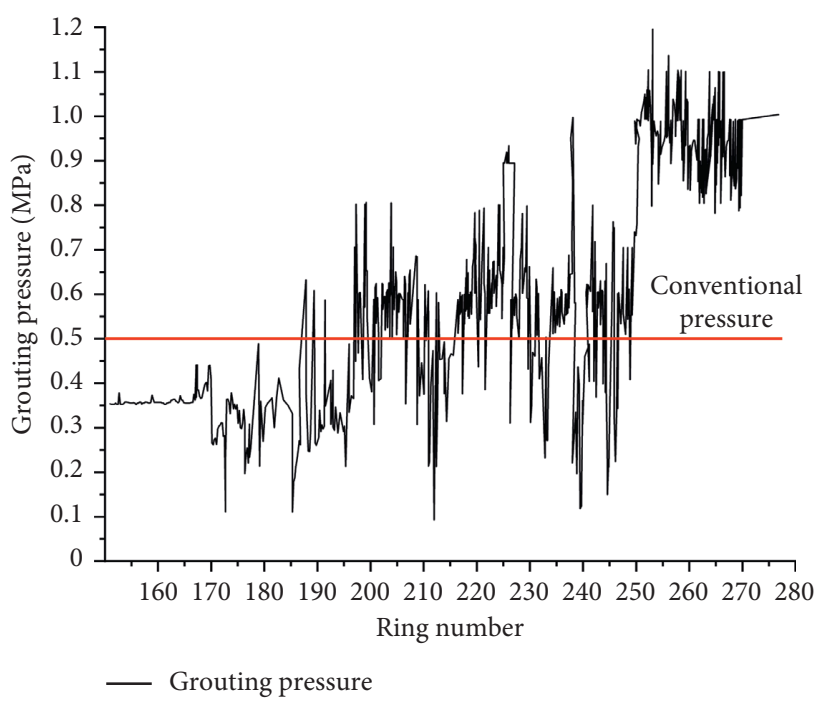

(b)

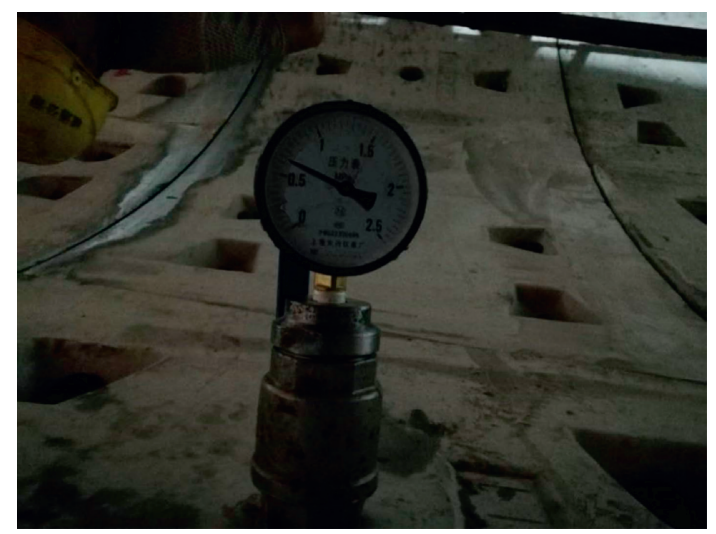

(d)

FIgURE 3: Field disease condition. (a) Seepage of the pipe segment. (b) Synchronous grouting pressure. (c) Flow condition of synchronous grouting line. (d) Field hydraulic test.

various places; (ii) although the grouting pressure increased, the slurry still could not be injected into the soil at some locations.

From the grouting pressure records of the grouting system, the grouting pressure diagram is shown in Figure 3(b). It shows that the grouting pressure was maintained at $0.25-0.40 \mathrm{MPa}$ before tunneling to ring 200, after which it increased significantly and remained above $0.50 \mathrm{MPa}$, even exceeding 1.00 MPa in many places. Based on related research [14], the simultaneous grouting pressure of a shield machine is closely related to the formation splitting pressure and overlying soil. The results show that a reasonable grouting pressure for a tunnel with a buried depth of $20 \mathrm{~m}$ is $0.32-0.42 \mathrm{MPa}$. Meanwhile, in previous tunnel construction in this area, reasonable grouting pressures were also within this range [15]. The above analysis indicates that a grouting pressure of $0.50 \mathrm{MPa}$ is abnormal. Given the appearance of MSL, we reason that the abnormal grouting pressure was caused by high water pressure.

Furthermore, when inspecting the grouting hole, a large amount of water poured in after the grouting hole was opened, as shown in Figure 3(c). To obtain the water pressure accurately, a pressure gauge with a range of $0-2.50 \mathrm{MPa}$ was installed in the grouting hole and measured the water pressure as being $0.60 \mathrm{MPa}$. Based on geological prospecting data, the groundwater in this area is from the phreatic and confined water at the lower part of the station, so the phreatic or confined water is the main cause of the engineering problems. The buried depth of the phreatic water is $2.0 \mathrm{~m}$ as obtained by calculating the water pressure according to Darcy's law, and the water pressure caused by the phreatic water is $0.20 \mathrm{MPa}$, which is significantly different from the measured value. Therefore, the MSL cannot be due to the phreatic groundwater but only the confined water.

However, according to geological survey data, the confined water is not near where the problems arose (rings 200-300) but rather is located mainly at a depth of $60 \mathrm{~m}$ below the station area (rings 50-150), as shown in Figure 1. Therefore, before finally causing leakage, the confined water must have flowed along a certain path to the problem zone. 
2.2. Analysis of the Flow Path of the Confined Water. According to the above analysis, the source of the MSL was the confined water, which flowed along a certain path and reached the leakage zone. Combined with the geological data and the site construction, the schematic of the specific situation from the station interval to the problem interval shown in Figure 4 was drawn. This shows that the confined water is distributed in the aquifer at a buried depth of $60 \mathrm{~m}$ below the station area (ring segments 50-150). However, the problems occurred in the strata behind the station interval (ring segments 200-300). Therefore, we must analyze the flow of the confined water, which we do here in stages in combination with Figure 4.

2.2.1. Upwelling Stage. As shown in Figure 4, below the station area is an aquifer (buried depth $60 \mathrm{~m}$ ) that contains a large amount of confined water and above which is the aquitard (buried depth $40-60 \mathrm{~m}$ ) that restricts the flow of that confined water. However, at the bottom of the station structure area are many engineering piles with a length of $70 \mathrm{~m}$. This pile foundation penetrates the aquitard, thereby allowing the confined water in the aquifer to rise along the pile holes and surge to the top of the tunnel.

2.2.2. Circulation Stage. After the upwelling confined water reaches the top of the tunnel, it is still a distance of $\sim 50-100$ rings from the leakage interval. For confined water to flow to the problem zone, there must be a UCWC as shown in Figure 4. This UCWC is analyzed in detail in Section 3.

2.2.3. Downwelling Stage. Figure 4 shows the presence of geological exploration boreholes in the strata behind the station. With a diameter of $200 \mathrm{~mm}$ and drilling to depths of 40-60 m, these exploration boreholes penetrate the silt and silt-clay and reach the vicinity of the tunnel. Having flowed along the UCWC to the formation above the problem zone, the confined water seeps down the boreholes and eventually into the tunnel segment to cause MSL.

The flow paths in the upwelling and downwelling stages can be verified from construction drawings and geological prospecting data. However, the UCWC must still be analyzed and verified.

2.3. Assumption on the Cause of UCWC. According to related research [16-21], different strata stiffnesses during tunnel excavation lead to settlement differences occurring under the influences of gravity stress and the tunnel excavation. As shown in Figure 5, the contact surfaces between different strata become weak structural surfaces that open under the action of stress. Finally, interlaminar fissures extend in the normal direction.

Based on the above research, we make the following assumptions about what caused the UCWC. During the tunnel excavation, settlement occurred in the strata surrounding the station structure. The many pile foundations in the lower part of the station structure strengthened the strata within a certain range by compression, while the rest of the strata remained weak. As shown in Figure 5, the difference in properties between the reinforced area and the soft soil layer resulted in different degrees of deformation under pressure. The amount of settlement changed suddenly on the weak structural surfaces, which opened in the normal direction where those changes were large, and the faults formed into a flow channel. In Section 3, we use numerical simulations and field measurements to support this hypothesis.

\section{Numerical Simulation Analysis of UCWC}

3.1. Establishment of the Model. To verify the hypothesis about the origin of the UCWC, we used the FLAC 3D FE software for modeling and analysis. Based on the UCWC assumption, we determined the main research area as being the interval strata through the station. Because of the large size of the complete station $(X \times Y=120 \mathrm{~m} \times 60 \mathrm{~m})$, we selected part of the tunnel through the station (i.e., segment rings $75-100$, buried depth $0-40 \mathrm{~m}$ ) for modeling for the convenience of calculation. The location is the area marked in Figure 5. Figure 6 shows the FE mesh of the model: Figure 6(a) is the three-dimensional diagram of the FE model, and Figure 6(b) is the section diagram of the model. The overall size of the model was $60 \mathrm{~m} \times 30 \mathrm{~m}$ $\times 40 \mathrm{~m}(X \times Y \times Z)$.

Based on the location and soil properties, the strata were divided as follows into five layers with a total depth of $40 \mathrm{~m}$ : (i) the station area (with a thickness of $5 \mathrm{~m}$ ), (ii) the reinforced area $(5 \mathrm{~m})$, (iii) the area of silt and silty soft soil $(5 \mathrm{~m})$, (iv) the silty clay area $(10 \mathrm{~m})$, and (v) the sandy silty clay area $(15 \mathrm{~m})$. The distribution is shown in Figure 6(b), and the physical parameters of each soil layer are given in Table 2 . Because of the existence of the raft pile foundation, the parameters of the reinforced area are improved. The elastic modulus of the pile foundation was converted by equivalent formula, and the parameters of the reinforced zone were obtained after calculation. The formula is shown below.

$$
E^{*} V^{*}=E_{1} V^{*}+E_{2} V_{2}
$$

where $E^{*}$ is the elastic modulus of the equivalent reinforced area (to be calculated), $V^{*}$ is the volume of the reinforced area $\left(9000 \mathrm{~m}^{3}\right), E_{1}$ is the initial elastic modulus of the reinforced area $(8.4 \mathrm{MPa}), E_{2}$ is the elastic modulus of the pile foundation ( $31500 \mathrm{MPa})$, and $V_{2}$ is the volume of all pile foundations in the model $\left(211 \mathrm{~m}^{3}\right)$.

The outer diameter of a tunnel segment was $6.2 \mathrm{~m}$, the inner diameter was $5.5 \mathrm{~m}$, and the buried depth was $20 \mathrm{~m}$. The numerical simulation of tunnel excavation was consistent with the actual situation on site. The specific steps were as follows: (i) the initial ground stress was balanced; (ii) the tunnel on the left was excavated first, after which segments were assembled; the length of each excavation was $1.2 \mathrm{~m}$; (iii) after the left tunnel had been excavated for 10 rings and assembled, excavation of the right tunnel began; in other words, both tunnels were excavated synchronously, with a distance of $1.2 \mathrm{~m}$ for each excavation, after which the pipe pieces were assembled immediately; (iv) the left tunnel was finished first, after which excavation of the right tunnel continued until it was also finished. The tunnel excavation 


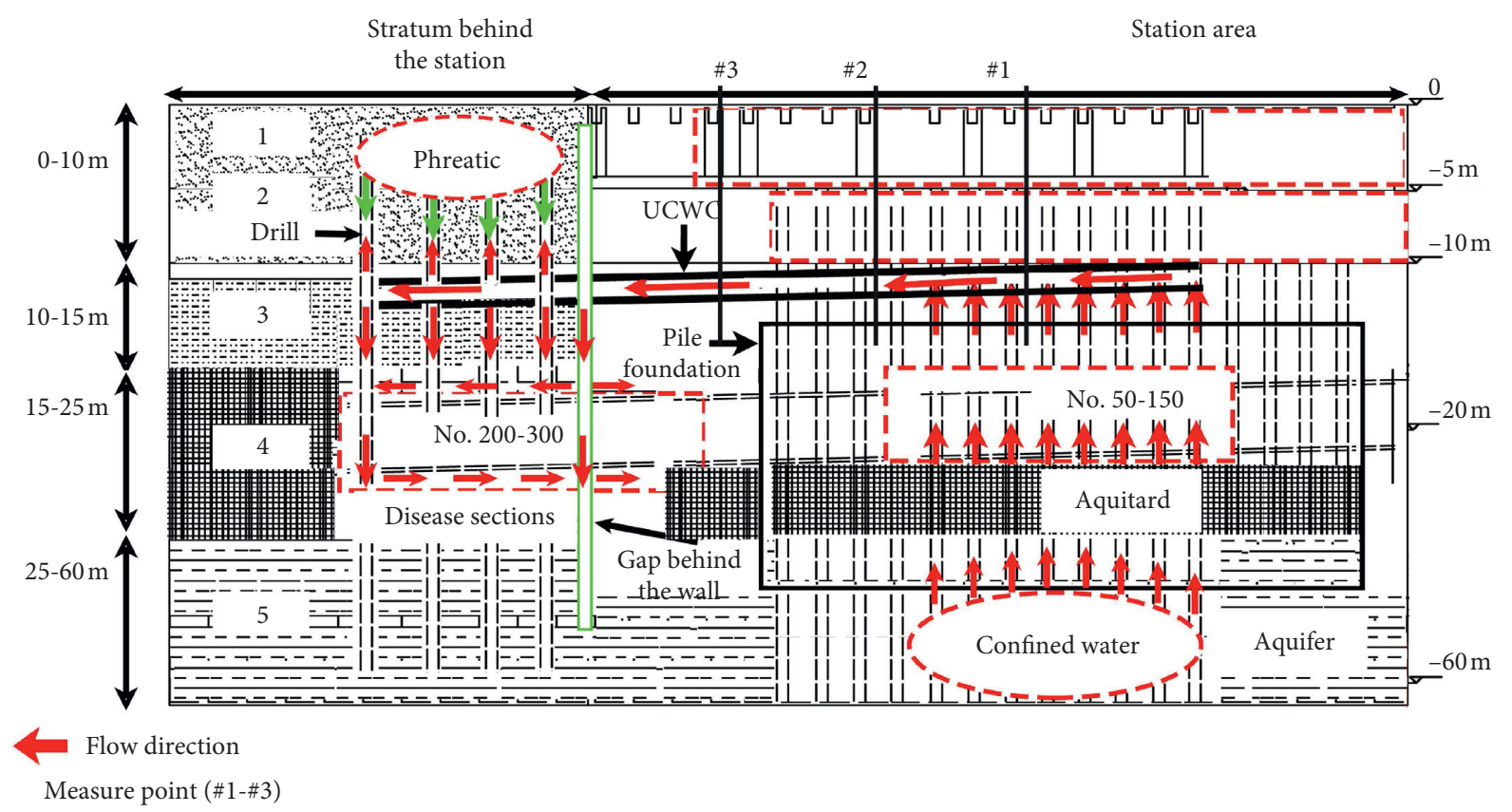

1.Station area

4.Silty clay

2.Reinforcement area

5.Silty clay with sand

3.Silt and silty clay

FIgURE 4: Schematic diagram of position.
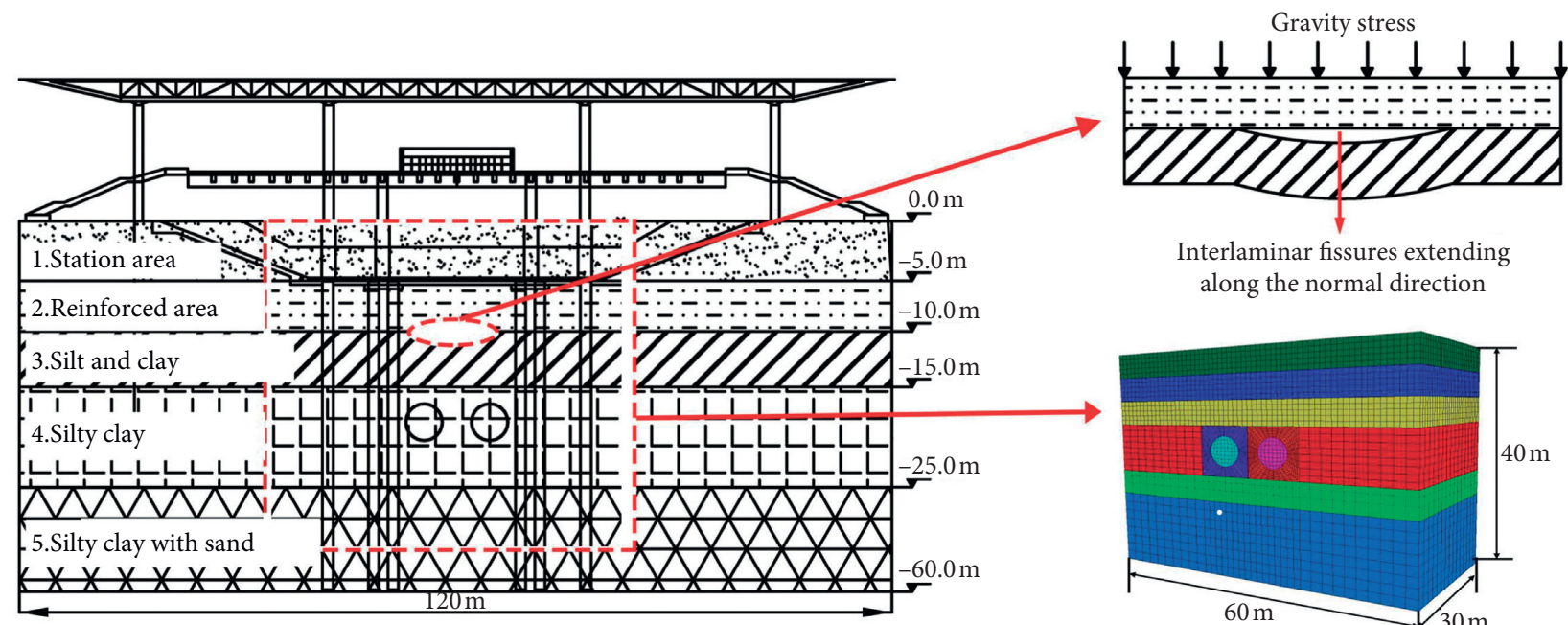

Interlaminar fissures extending along the normal direction

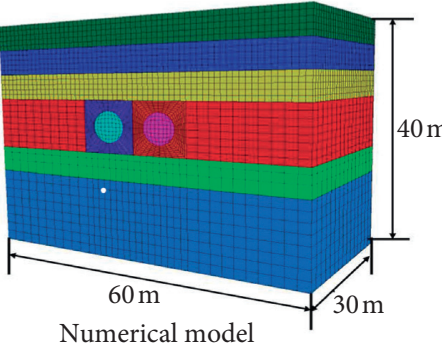

FIGURE 5: Interlaminar fissures.

and the assembling of the pipe pieces were simulated by means of killing zones and activating shells. A shield tunnel segment was a C50 reinforced-concrete tube segment with a thickness of $0.35 \mathrm{~m}$ and a width of $1.2 \mathrm{~m}$. The physical parameters of the tunnel segments and the underground structure of the station are given in Table 3.

The following basic assumptions were used in the modeling. (1) Solid elements were used in the model to simulate the strata, which obeyed the Mohr-Coulomb yield criterion. (2) The underground structure of the station was simulated by solid elements that were modeled separately and obeyed the linear elasticity criterion. (3) Shell units were used to simulate the lining structure of the shield tunnel. (4) The surface and the surrounding layers were uniformly layered and distributed. (5) The interface unit was simulated at the critical plane of the reinforced area. (6) The left and right boundaries were constrained by the $X$-direction displacement, and the front and rear boundaries were constrained by the $Y$ - and $Z$-direction displacements of the bottom boundary. 


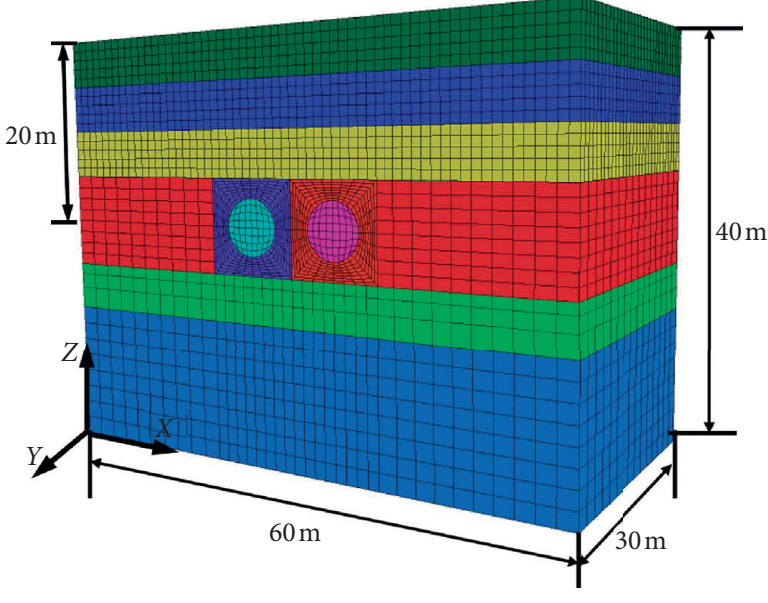

(a)

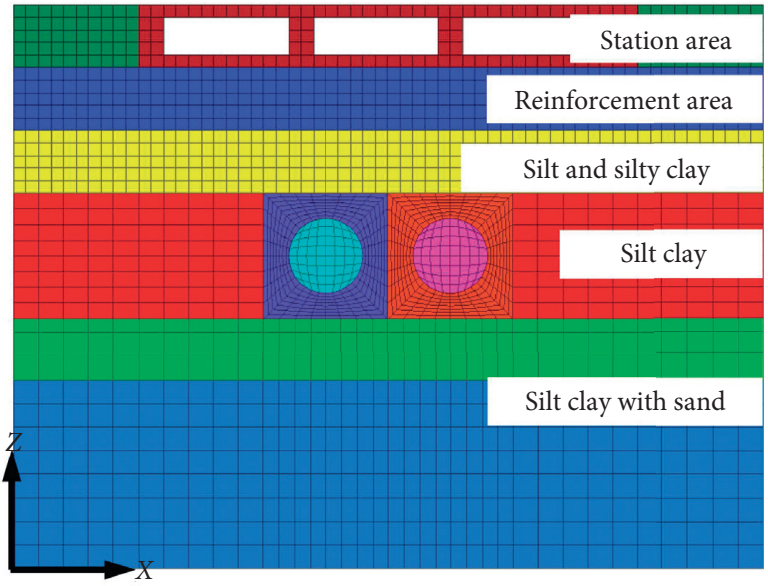

(b)

FIgURE 6: Schematic diagram of the model. (a) Three-dimensional diagram. (b) Strata distribution profile.

TABLe 2: Mechanical parameters of strata.

\begin{tabular}{|c|c|c|c|c|c|c|c|}
\hline No. & Strata & $\begin{array}{l}\text { Thickness } \\
(\mathrm{m})\end{array}$ & $\begin{array}{c}\text { Density (kg/ } \\
\left.\mathrm{m}^{3}\right)\end{array}$ & $\begin{array}{l}\text { Bulk modulus } \\
(\mathrm{MPa})\end{array}$ & $\begin{array}{l}\text { Shear modulus } \\
(\mathrm{MPa})\end{array}$ & $\begin{array}{c}\text { Cohesion } \\
(\mathrm{kPa})\end{array}$ & $\begin{array}{c}\text { Friction angle } \\
\left({ }^{\circ}\right)\end{array}$ \\
\hline 1 & Station area & 5.0 & 2480 & 5.6 & 1.2 & 15 & 48 \\
\hline 2 & $\begin{array}{c}\text { Reinforcement } \\
\text { area }\end{array}$ & 5.0 & 2400 & 210 & 95 & 15 & 15 \\
\hline 3 & Silt and silty clay & 10.0 & 1900 & 15 & 7.2 & 15 & 36 \\
\hline 4 & Silty clay & 5.0 & 1910 & 12.9 & 5.9 & 40 & 40 \\
\hline 5 & Silty clay with sand & 15.0 & 2010 & 25 & 11.5 & 400 & 43 \\
\hline
\end{tabular}

TABLE 3: Mechanical parameters of underground structure.

\begin{tabular}{lcccc}
\hline No. & Structure & Thickness $(\mathrm{m})$ & Density $\left(\mathrm{kg} / \mathrm{m}^{3}\right)$ & Elastic modulus $(\mathrm{MPa})$ \\
\hline 1 & Roof & 1 & 2500 & 3000 \\
2 & Wall & 1 & 2550 & 3000 \\
3 & Foundation & 3 & 2550 & 3000 \\
4 & Segment & 0.35 & 2500 & 34500 \\
\hline
\end{tabular}

3.2. Analysis of Simulation Results. Having established the numerical model, the simulation was carried out according to the excavation situation of the tunnel. Through numerical calculation, the results were obtained and analyzed. To analyze the process whereby the UCWC developed with the tunnel excavation, Figure 7 shows a cloud map of the different excavation stages at the position of ring 90. As shown in Figure 7, with excavation of the left tunnel, obvious deformation occurred above the tunnel, the deformation at the interface between the reinforced zone and the soft soil layer was abnormal, and there were faults directly above the tunnel. With excavation of the right tunnel, the location of the interface above the right tunnel also changed suddenly, and the abrupt areas above the tunnel on the left and right sides were connected. As the tunnels on both sides were excavated simultaneously until the end of the excavation, the abrupt area always existed.

Also, to analyze the spatial location distribution of the UCWC and obtain a preliminary understanding of the settlement deformation, we selected the cross section cloud map of the 90th circular pipe section of the tunnel, as shown in Figure 8(a), from which we see the following. (1) The settlement in the station and reinforced areas was small, being mostly around $5 \mathrm{~mm}$ and never exceeding $10 \mathrm{~mm}$. Also, the settlement change in this part of the area was continuous, without abrupt change; this was because the soil properties of this area were reinforced by the pile foundation. (2) Deformation of the soft soil layers under the reinforced area was uniform and continuous. Moreover, it was affected greatly by the tunnel excavation, and a large settlement deformation of $10-30 \mathrm{~mm}$ occurred in the area surrounding the tunnel. The largest settlement deformation of up to $25.12 \mathrm{~mm}$ occurred in the tunnel arch. (3) Because of the large differences in properties between the soft soil layer and the soil in the strengthened area, the deformation between the soft soil layer and the strengthened area was discontinuous and abrupt changes occurred. The settlement at the bottom of the reinforced area was $5-10 \mathrm{~mm}$, but that in the silt and silty clay at the top changed suddenly to more than $15 \mathrm{~mm}$. The area with a large settlement difference was concentrated directly above the tunnel. 


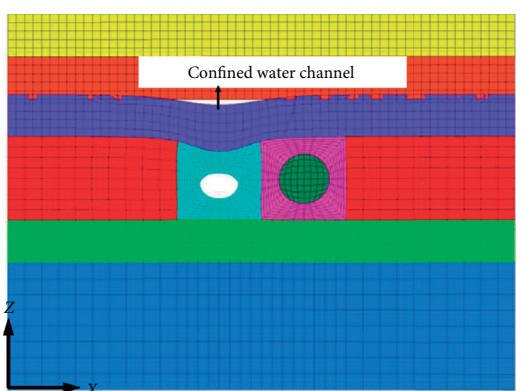

(a)

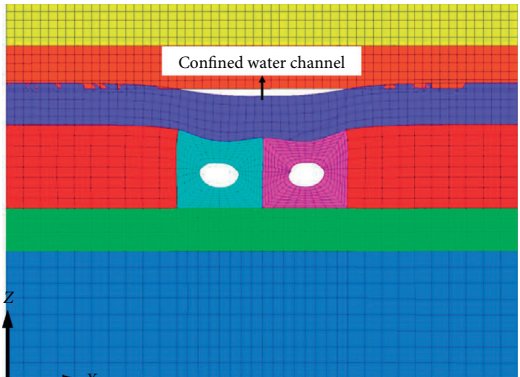

(b)

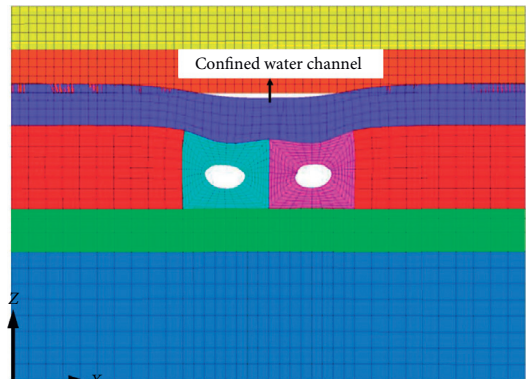

(c)

FIgURE 7: : Schematic diagram of channel formation. (a) Left side excavation; (b) right side excavation; (c) simultaneous excavation.

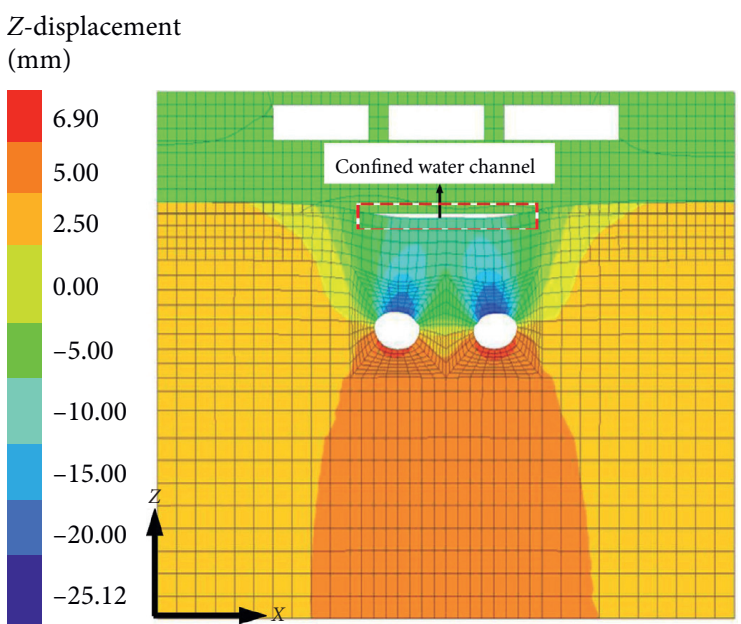

(a)

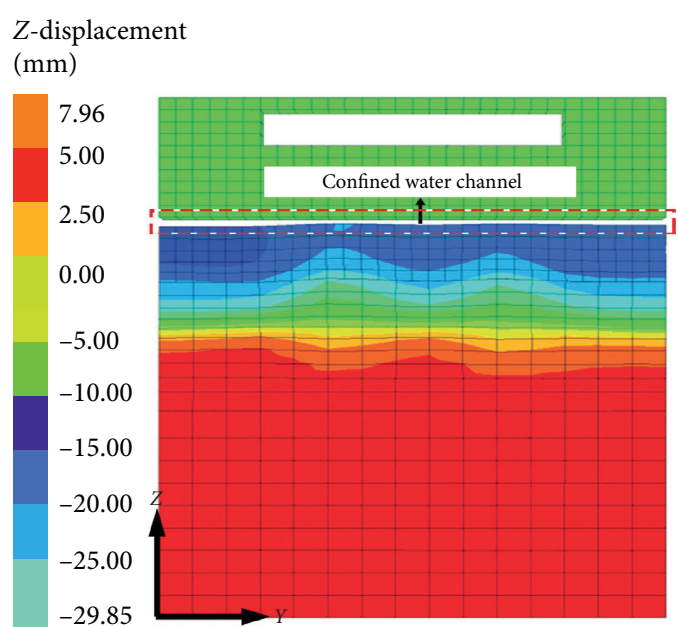

(b)

Figure 8: : Diagram of deformation. (a) Diagram of cross section; (b) diagram of longitudinal section.

The longitudinal cloud diagram was intercepted along the center of the model, as shown in Figure 8(b), which shows the following. (1) The settlement among all layers was consistent with that of Figure 8(a). The amount of settlement above the reinforced area was small, with values of $0-5 \mathrm{~mm}$. The lower part of the soft soil area had a large settlement of $10-30 \mathrm{~mm}$. (2) Fissures appeared in the interface of the reinforced area and the channel and silty clay and became connected along the direction of tunnel excavation.

Figures 7 and 8 give an initial intuitive understanding of the distribution of the UCWC, but the specific deformation values of various layers, including surface subsidence, cannot be analyzed quantitatively. Therefore, we extracted specific data on the different buried depths at the pipe slice of ring 90 and plotted Figure 9(a) to analyze further the numerical deformation law. The rules are as follows. (1) The surface settlement (the settlement curve at $Z=0 \mathrm{~m}$ ) was affected less by the tunnel excavation, and the overall change was relatively uniform, remaining at $4 \mathrm{~mm}$. (2) The subsidence of the station area was slightly larger than the surface subsidence, with a value of $6 \mathrm{~mm}$. (3) The overall settlement in the reinforced area was small, with a value of $8 \mathrm{~mm}$. (4) In the area with a buried depth of $10-15 \mathrm{~m}$, the settlement deformation was obviously affected by the tunnel excavation, with a maximum subsidence value of $22 \mathrm{~mm}$ and an obvious $\mathrm{W}$ shape at the center of the tunnel, which conforms to the theory of a $\mathrm{W}$-shaped subsidence trough [22-26]. (5) The deformation of the silty clay area $(Z=15-25 \mathrm{~m})$ was in line with a Gaussian settlement curve. (6) A settlement difference was found between the reinforced area and the silty clay. The amounts of settlement above and below the interface were approximately 8 and $19 \mathrm{~mm}$, respectively, corresponding to a settlement difference of approximately $11 \mathrm{~mm}$.

To understand the numerical development law of the settlement difference, we plotted Figure 9(b), which shows that, after the left tunnel was excavated, the settlement difference was $11.1 \mathrm{~mm}$. This was distributed above the left tunnel and increased to $13.3 \mathrm{~mm}$ as the right tunnel was excavated, and the distribution area also began to extend to the right tunnel. After the synchronous excavation, the settlement difference tended to decrease, ranging from 11.7 to $12.0 \mathrm{~mm}$. After the excavation, the settlement difference was stable at $10.9 \mathrm{~mm}$ and was concentrated above the two tunnels.

In summary, the hypothesis about the UCWC is shown to be correct. The large differences in soil properties led to differential settlement during tunnel excavation, and a 


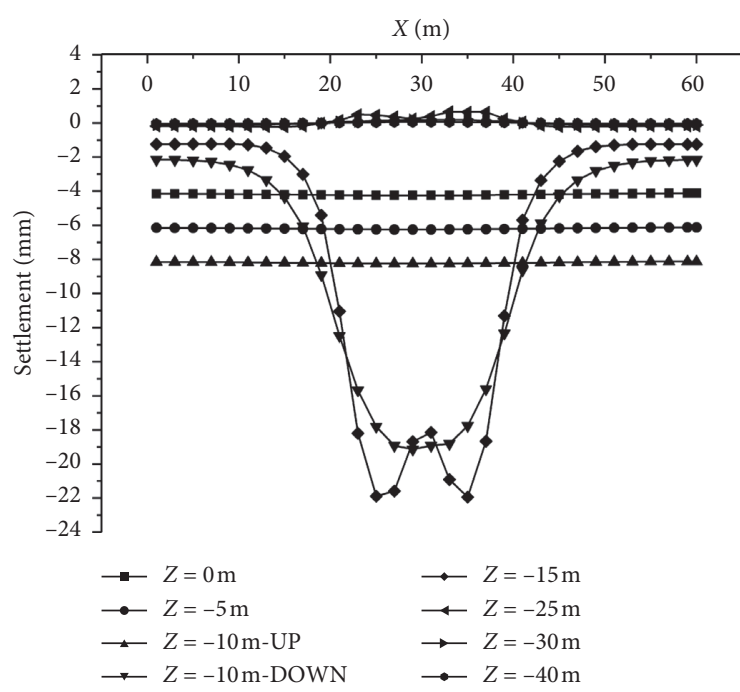

(a)

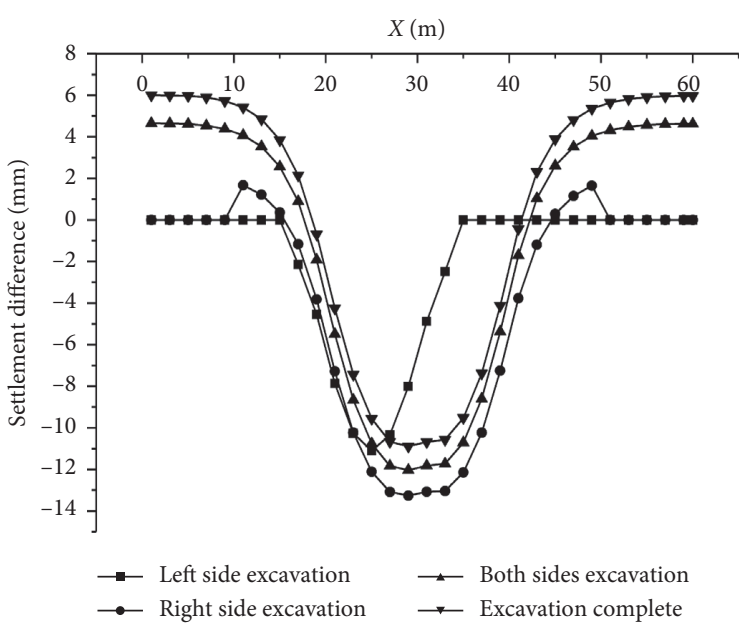

(b)

Figure 9: Settlement curve. (a) Settlement of different depths; (b) settlement difference of each step.

laminar fissure of $8-10 \mathrm{~mm}$ formed. Under the action of confined water, the fissure developed to form a channel for the flow of confined water, which eventually led to engineering problems.

3.3. Verification of Field Measurement Data. To ensure safe construction, staff at the project site conducted real-time monitoring of the subway tunnel under the SRS section. The stratified settlement at the center position of the two tunnels was chosen for measurement, and the measuring points were arranged at the positions of rings 90, 140, and 190, corresponding to measuring points 1-3, respectively, in Figure 4. The stratified settlement was monitored using a telescoping tube settlement gauge.

It is extracting the field measured value of the measurement points and simulated values of the numerical model, drawing a diagram of curves as shown in Figure 10. These show that the layered settlements at the positions of rings 90, 140, and 190 have basically the same variation trends. The three measuring points all indicated that the abrupt subsidence change occurred at the boundary between the reinforced area and the weak strata. The settlement difference of the boundary surface at the position of ring 90 was $8.62 \mathrm{~mm}$, that at ring 140 was $9.95 \mathrm{~mm}$, and that at ring 190 was $8.4 \mathrm{~mm}$. The settlement differences at these three measuring points indicate that, along the direction of tunnel excavation, there was always a large settlement difference at the interface. That is, the UCWC extended along the direction of tunnel excavation, which is consistent with the spatial distribution rule obtained by numerical simulation in Figure 8(b).

Also, the numerical simulation results are validated by comparing the simulated numerical values at the position of ring 90 with the field measurements in Figure 10. Ring 90 was chosen for this comparison because the spatial simulation range of the numerical model covered the positions of rings 75-100. Figure 10 shows that the measured surface

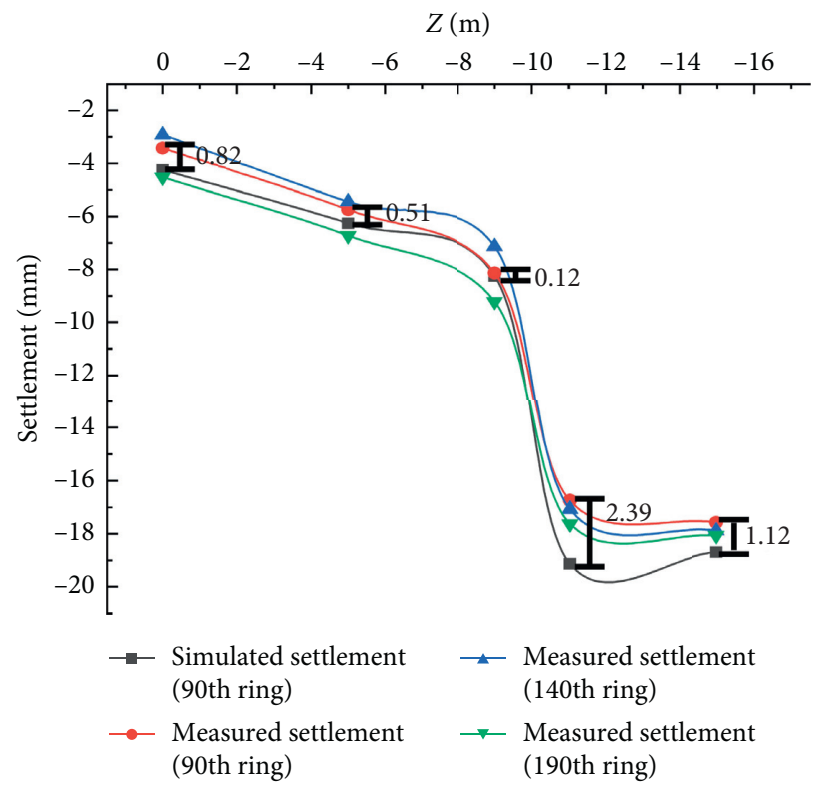

Figure 10: Comparison of data.

settlement was $3.42 \mathrm{~mm}$ while the corresponding simulated value was $4.24 \mathrm{~mm}$, and the settlement measured at $5 \mathrm{~m}$ depth was $5.74 \mathrm{~mm}$ while the corresponding simulated value was $6.25 \mathrm{~mm}$. The settlement changed dramatically at the boundary surface of the strata with a buried depth of $10 \mathrm{~m}$. The measured value above the boundary surface was $8.13 \mathrm{~mm}$ while the corresponding simulated value was $8.25 \mathrm{~mm}$. The measured value below the interface was $16.75 \mathrm{~mm}$ while the corresponding simulated value was $19.14 \mathrm{~mm}$. The measured value of settlement at a depth of $15 \mathrm{~m}$ was $17.57 \mathrm{~mm}$ while the corresponding simulated value was $18.69 \mathrm{~mm}$. The deviation between the measured and simulated values at different buried depths is marked in Figure 10, which shows the numerical deviations as being 


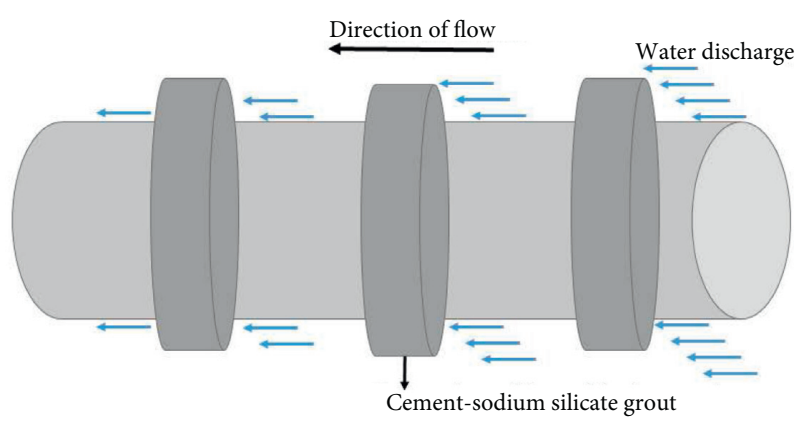

FIGURE 11: Schematic diagram of mechanism.

$0.82,0.51,0.12,2.39$, and $1.12 \mathrm{~mm}$. Most of these numerical differences were around $1 \mathrm{~mm}$, and the largest was $2.39 \mathrm{~mm}$, which appeared in the subsidence mutation region.

Although the measured and simulated values deviate somewhat at the interface, their overall variation trends are consistent. Regardless of whether the numerical simulation results or the measured values are considered, the settlement for buried depths of $0-10 \mathrm{~m}$ is small and uniformly continuous, with sharp changes in the position of the boundary surface at $10 \mathrm{~m}$ and then returning gradually to a uniform and continuous state. Also, the numerical simulation errors of $1-3 \mathrm{~mm}$ are considered acceptable in practical engineering applications [27], so these results are applicable in that context.

At the same time, water composition analysis was carried out to further determine the water source in the leakage zone based on the Code for Water Analysis of Railway Engineering. The components of the disease zone were analyzed, such as $\mathrm{SO}_{4}{ }^{2-}, \mathrm{Mg}^{2+}, \mathrm{CO}_{2}, \mathrm{Cl}^{-}, \mathrm{pH}$, and total salinity, and then the composition indexes of the confined and phreatic water in this area were examined. Finally, the compositions of three water samples were compared. Statistics for the equipment, reagents, test methods, and analysis results for the water composition analysis are given in Table 4. Comparison shows that the values of $\mathrm{SO}_{4}{ }^{2-}, \mathrm{Mg}^{2+}, \mathrm{pH}$ value, and erosion $\mathrm{CO}_{2}$ for the water sample from the problem range were close to those for the confined water sample and significantly higher than those for the submerged water sample, while the values of $\mathrm{Cl}^{-}$and total salinity were lower than those for the confined water sample but higher than those for the submerged water sample.

The above suggests that the water in the leakage zone was confined water that was upwelling along the sides of the borehole perfusion piles already constructed in SRS. The results of the water composition analysis determined that the leakage was caused by the flow of interval confined water; i.e., the existence of the UCWC caused confined water within the station interval (rings 50-150) to flow to the problem interval, which verifies the UCWC hypothesis.

\section{Technical Measures and Effects}

From analyzing the MSL, we reasoned that the problem was caused by the circulation of confined water leading to serious water leakage that waterproofing and synchronous grouting alone could not address. To ensure safe tunnel operation, we made the following suggestions.
(1) The synchronous grouting material should be changed from the original inert slurry material to active slurry material, and cement slurry should be used to increase the stone rate and strength.

(2) Long-tube binary grouting should be used in the leakage section to carry out radial secondary grouting reinforcement in the $3.5 \mathrm{~m}$ range around the section tunnel segment so that the void is filled with slurry and consolidated to improve the surrounding rock. This would form hoop protection on the outer circumference of the tunnel, thereby cutting off the UCWC and weakening the influence of water seepage on the tunnel, as shown in Figure 11.

(3) Using new grouting material, the initial setting time, hardening rate, early strength, late strength, and impermeability of the grouting material are the key parameters affecting its application effectiveness. Sulphoaluminate cement should be used for this application.

(4) Given that monitoring is essential in construction, the monitoring and measurement should be strengthened. During the grouting process, it is necessary to monitor in time, pay close attention to the deformation of the strata after grouting, and adjust the grouting parameters in time.

(5) Because the physical characteristics of the strata in the Hangzhou area are similar to those in the Shanghai area, the construction of jet grouting with a triple fluid system-twin jet in the Shanghai area should be used for reference. Meanwhile, in the design stage of jet grouting, relevant methods should be used to reasonably estimate the excess pore water pressure and the influence of jet grouting on ground movement [28-34].

These technical measures were adopted and grouting material tests were carried out. The synchronous grouting material was changed from inert slurry to active slurry, and a second grouting was carried out. The site construction drawing is shown in Figure 12(a). After the measures were taken, good results were achieved, cutting off the flow channel and reducing the occurrence of MSL effectively, as shown in Figure 12(b).

The present practice showed that discovering and cutting off the UCWC are the key to preventing MSL in the later stage. On this basis, the technical measure of sectional 
TABLE 4: Main indicators of water composition analysis.

\begin{tabular}{|c|c|c|c|c|c|c|}
\hline \multicolumn{7}{|c|}{ Composition } \\
\hline Item & $\mathrm{SO}_{4}{ }^{2-}(\mathrm{mg} / \mathrm{L})$ & $\mathrm{Mg}^{2+}(\mathrm{mg} / \mathrm{L})$ & $\begin{array}{l}\text { Total } \\
\text { salinity } \\
(\mathrm{mg} / \mathrm{L})\end{array}$ & $\mathrm{pH}$ & $\mathrm{CO}_{2}(\mathrm{mg} / \mathrm{L})$ & $\mathrm{Cl}^{-}(\mathrm{mg} / \mathrm{L})$ \\
\hline $\begin{array}{l}\text { Instrument } \\
\text { and } \\
\text { equipment }\end{array}$ & \multicolumn{6}{|c|}{ Conical flask, pipette, burette, volumetric flask, acidity meter and matching compound electrode, evaporating dish } \\
\hline Reagent & $\begin{array}{c}\mathrm{HCl} \text { solution, } \\
\text { EDTA-2 } \mathrm{Na} \\
\text { solution, solution of } \\
\mathrm{Ba} \text { and } \mathrm{Mg}\end{array}$ & $\begin{array}{l}\text { Ammonium buffer } \\
\text { solution, chromium black } \\
\text { solid indicator, } \mathrm{Na}_{2} \mathrm{~S} \\
\text { solution }\end{array}$ & $\begin{array}{c}1 \% \\
\mathrm{Na}_{2} \mathrm{CO}_{3} \\
\text { solution }\end{array}$ & $\begin{array}{l}\text { Standard buffer } \\
\text { solution, saturated } \\
\mathrm{KCl} \text { solution }\end{array}$ & $\begin{array}{c}\mathrm{CaCO}_{3} \text { powder, } \\
\text { indicator, } \\
\mathrm{Na}_{2} \mathrm{CO}_{3} \text { solution, } \\
\mathrm{HCl} \text { solution }\end{array}$ & $\begin{array}{c}\mathrm{K}_{2} \mathrm{CrO}_{4} \\
\text { indicator, } \mathrm{NaCl} \\
\text { solution, } \mathrm{AgNO}_{3} \\
\text { solution }\end{array}$ \\
\hline Method & Volumetric method & $\begin{array}{c}\text { EDTA-2Na } \\
\text { complexometric titration }\end{array}$ & $\begin{array}{l}\text { Weight } \\
\text { method }\end{array}$ & $\begin{array}{l}\text { Acidometer } \\
\text { titration }\end{array}$ & $\begin{array}{c}\text { Acid-base } \\
\text { titration }\end{array}$ & $\begin{array}{l}\mathrm{AgNO}_{3} \\
\text { volumetric } \\
\text { method }\end{array}$ \\
\hline $\begin{array}{l}\text { Leakage } \\
\text { section }\end{array}$ & 84.50 & 274.87 & 1418 & 6.44 & 11.31 & 722.62 \\
\hline Phreatic water & 10.96 & 13.45 & 149 & 7.26 & 3.51 & 23.13 \\
\hline $\begin{array}{l}\text { Confined } \\
\text { water }\end{array}$ & 72.45 & 226.38 & 5094 & 6.63 & 7.02 & 2838.23 \\
\hline
\end{tabular}

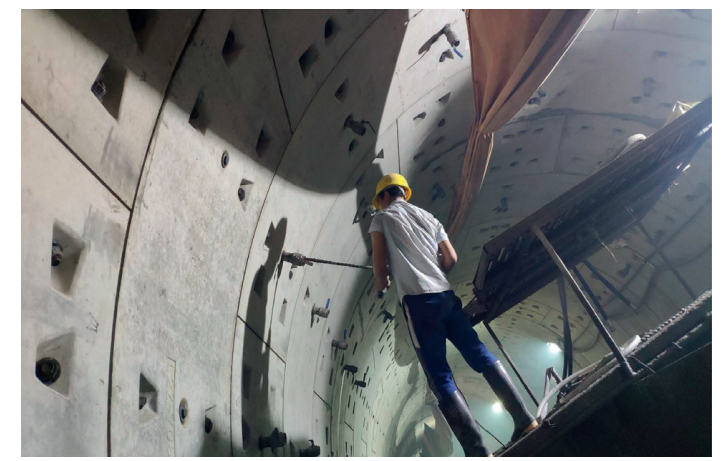

(a)

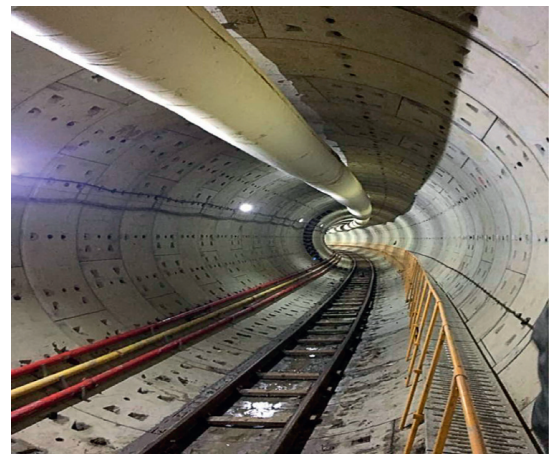

(b)

FIgURe 12: : Photographs of site construction and effect. (a) Scene of secondary grouting. (b) The condition of the pipe after grouting.

grouting was proposed, and good results were achieved in practical engineering. The present research results have a certain reference value for similar projects.

\section{Conclusions}

Based on the Hangzhou Metro Line 5 project, herein we analyzed the MSL problems in the project by means of field investigations, geological data, numerical simulations, and monitoring measurements, and we draw the following conclusions:

(1) The source of the MSL problem was confined water, not phreatic water. The flow of confined water leads to the occurrence of engineering problems.

(2) Reinforcing the foundation in the station area led to differences in the properties of different rock strata. Under the action of excavation and disturbance, the settlement difference was increased further and laminar flow fractures formed, forming a UCWC. By analyzing the settlement characteristics of the tunnel excavation, the settlement values between strata were obtained where the tunnel passes under the reinforced structure. The field monitoring data further verified the UCWC hypothesis.

(3) The technical measure of sectional grouting is effective in alleviating the MSL problem and is effective in practical engineering.

However, this study has the following shortcomings. Although the trends of the results from the numerical simulations and field measurements verified the UCWC hypothesis, the numerical model simulated a relatively ideal situation without considering other factors in construction, which resulted in a certain deviation between the numerical simulation results and the measured data.

\section{Data Availability}

The data used to support the findings of this study are available from the corresponding author upon request. 


\section{Conflicts of Interest}

The authors declare that there are no conflicts of interest regarding the publication of this paper.

\section{Acknowledgments}

This paper was financially supported by the National Natural Science Foundation of China (Grant no. 51978582).

\section{References}

[1] J. Bai, S. Li, and R. Liu, "Multi-field information monitoring and warning of delayed water bursting in deep rock fault," Chinese Journal of Rock Mechanics and Engineering, vol. 34, no. 11, pp. 93-104, 2015.

[2] F. Ye, F. Liu, and K. Li, "Mechanism and prevention of water leakage in tunnel engineering," Railway Engineering, vol. 12, pp. 51-55, 2007.

[3] J. Xu, C. He, and W. Xia, "Research on coupling seepage field and stress field analyses of underwater shield tunnel," Rock and Soil Mechanics, vol. 30, no. 11, pp. 3519-3527, 2009.

[4] Z. Wang, Y. Gao, and L. Li, "Analysis and engineering application of seepage characteristics of tunnel fissure water," Journal of China \& Foreign Highway, vol. 28, pp. 207-211, 2008.

[5] T. Wang, X. Han, and Z. Qian, "Analysis of seepage problems in tunnel engineering," Chinese Journal of Underground Space and Engineering, vol. 4, no. 3, pp. 421-425, 2008.

[6] M. Li, H. Chen, and S. Ye, "Coupling mechanism analysis on cavern tunnel disease forming," Journal of Chongqing Jiaotong University (Natural Science), vol. 27, no. 2, pp. 228-232, 2008.

[7] G. Wei and W. Jiang, "A review of the causes and hazards of shield tunnel leakage," Low Temperature Architecture Technology, vol. 39, no. 11, pp. 157-160, 2017.

[8] J. H. Shin, T. I. Addenbrooke, and D. M. Potts, "A numerical study of the effect of groundwater movement on long-term tunnel behaviour," Géotechnique, vol. 52, no. 6, pp. 391-403, 2002.

[9] X.-X. Liu, S.-L. Shen, Y.-S. Xu, and Z.-Y. Yin, “Analytical approach for time-dependent groundwater inflow into shield tunnel face in confined aquifer," International Journal for Numerical and Analytical Methods in Geomechanics, vol. 42, no. 4, pp. 655-673, 2018.

[10] H. Wu, S. Shen, R. Chen, and A. Zhou, "Three-dimensional numerical modelling on localised leakage in segmental lining of shield tunnels," Computers and Geotechnics, vol. 122, Article ID 103549, 2020.

[11] J.-H. Shin, S.-H. Kim, and Y.-S. Shin, "Long-term mechanical and hydraulic interaction and leakage evaluation of segmented tunnels," Soils and Foundations, vol. 52, no. 1, pp. 38-48, 2012.

[12] Y.-X. Wu, H.-M. Lyu, S.-L. Shen, and A. Zhou, "A threedimensional fluid-solid coupled numerical modeling of the barrier leakage below the excavation surface due to dewatering," Hydrogeology Journal, vol. 28, no. 4, pp. 1449-1463, 2020.

[13] Y. Wu, S. Shen, H. Lyu, and A. Zhou, "Analyses of leakage effect of waterproof curtain during excavation dewatering," Journal of Hydrology, vol. 583, Article ID 124582, 2020.

[14] C. Zhu, "The influence of high pressure aquifer on construction of Hangzhou subwayand its countermeasures," Journal of Railway Engineering Society, vol. 7, no. 1, pp. 105-109, 2014.
[15] T. Song, S. Zhou, and R. Xu, "Mechanism and determination of parameters of synchronous grouting in shield tunneling," Chinese Journal of Underground Space and Engineering, vol. 4, no. 1, pp. 130-133, 2008.

[16] J. Chen, Q. Wu, and L. Yin, "Law of crack evolution in floor rock mass above high confined water," Coal Science and Technology, vol. 46, no. 7, pp. 54-60, 2018.

[17] R. Chen, X. Zhao, Z. Wang, H. Jiang, and X. Bian, "Experimental study on dynamic load magnification factor for ballastless track-subgrade of high-speed Railway," Journal of Rock Mechanics and Geotechnical Engineering, vol. 5, no. 4, pp. 306-311, 2013.

[18] J. Liu, T. Qi, and Z. Wu, "Analysis of ground movement due to metro station driven with enlarging shield tunnels under building and its parameter sensitivity analysis," Tunnelling and Underground Space Technology, vol. 28, pp. 287-296, 2012.

[19] C. Zhang, C. Pu, R. Cao, T. Jiang, and G. Huang, "The stability and roof-support optimization of roadways passing through unfavorable geological bodies using advanced detection and monitoring methods, among others, in the sanmenxia bauxite mine in China's Henan Province," Bulletin of Engineering Geology and the Environment, vol. 78, no. 7, pp. 5087-5099, 2019.

[20] C. Zhang, Y. Wang, H. Ruan, B. Ke, and H. Lin, "The strain characteristics and corresponding model of rock materials under uniaxial cyclic load/unload compression and their deformation and fatigue damage analysis," Archive of Applied Mechanics, vol. 17, pp. 306-321, 2021.

[21] C. Zhang, Y. Wang, and T. Jiang, "The propagation mechanism of an oblique straight crack in a rock sample and the effect of osmotic pressure under in-plane biaxial compression," Arabian Journal of Geosciences, vol. 13, no. 15, 2020.

[22] G. Preisig, A. Dematteis, R. Torri, N. Monin, E. Milnes, and P. Perrochet, "Modelling discharge rates and ground settlement induced by tunnel excavation," Rock Mechanics and Rock Engineering, vol. 47, no. 3, pp. 869-884, 2014.

[23] X. Liang, T. Qi, T. Qi, Z. Jin, and W. Qian, "Hybrid support vector machine optimization model for inversion of tunnel transient electromagnetic method," Mathematical Biosciences and Engineering, vol. 17, no. 4, pp. 3998-4017, 2020.

[24] Z. He, D. Xiang, Y. Liu, Q. Gao, and H. Bian, "Deformation behavior of coarse-grained soil as an embankment filler under cyclic loading," Advances in Civil Engineering, vol. 2020, Article ID 4629105, 13 pages, 2020.

[25] Z.-M. He, Z.-F. Liu, X.-H. Liu, and H.-B. Bian, "Improved method for determining active earth pressure considering arching effect and actual slip surface," Journal of Central South University, vol. 27, no. 7, pp. 2032-2042, 2020.

[26] J. Huang, Y. Xu, and S. Shen, "Strata deformation behaviors analysis caused by deep excavation of A metro station in sand covered karst strata," Chinese Journal of Underground Space and Engineering, vol. 13, no. 6, pp. 1639-1644, 2017.

[27] "Technical Code for Monitoring Measurement of Subway Engineering," DB11/490-2007.

[28] Z. Wang, S. Shen, G. Modoni, and A. Zhou, "Excess pore water pressure caused by the installation of jet grouting columns in clay," Computers and Geotechnics, vol. 125, Article ID 103667, 2020.

[29] K. Elbaz, S. Shen, A. Zhou, Z. Yin, and H. Lyu, "Prediction of disc cutter life during shield tunneling with ai via the incorporation of a genetic algorithm into a gmdh-type neural network," Engineering, vol. 7, pp. 238-251, 2020. 
[30] Z.-F. Wang, S.-L. Shen, and G. Modoni, "Enhancing discharge of spoil to mitigate disturbance induced by horizontal jet grouting in clayey soil: theoretical model and application," Computers and Geotechnics, vol. 111, pp. 222-228, 2019.

[31] B. Yuan, M. Sun, L. Xiong, and Q. Luo, "Investigation of 3D deformation of transparent soil around a laterally loaded pile based on a hydraulic gradient model test," Journal of Building Engineering, vol. 28, Article ID 101024, 2020.

[32] R. Cao, H. Lin, and Q. Lin, "Failure mechanism of nonpersistent jointed rock-like specimens under uniaxial loading: laboratory testing," International Journal of Rock Mechanics and Mining Sciences, vol. 132, Article ID 104341, 2020.

[33] R. Cao, R. Yao, T. Hu, C. Wang, K. Li, and J. Meng, "Failure and mechanical behavior of transversely isotropic rock under compression-shear tests: laboratory testing and numerical simulation," Engineering Fracture Mechanics, vol. 241, Article ID 107389, 2020.

[34] R. Cao, C. Wang, and R. Yao, "Effects of cyclic freeze-thaw treatments on the fracture characteristics of sandstone under different fracture modes: laboratory testing," Theoretical and Applied Fracture Mechanics, vol. 109, Article ID 102738, 2020. 